\title{
Holisme en totaliteit
}

\author{
P M Venter \\ Universiteit van Pretoria
}

\begin{abstract}
Holism and totality
\end{abstract}

As a contribution to the debate on postmodernism and holism, the viewpoint of J C Smuts is firstly summarised in this paper. Next, this summary is used to define on a comparative basis the viewpoint on totality found in the didactic poems of Proverbs 1-9. In conclusion an intertextual reading programme is proposed which should include the literature of Proverbs to enable one to form a theological viewpoint on holism.

\section{INLEIDING}

Die hede word dikwels as die tyd van die postmodernisme getipeer. Vir hierdie tyd word gesoek na 'een of ander vorm van ' $n$ holistiese of deelnemende bewussyn' (Schoeman 1990:273). Generaal J C Smuts het al in 1926 so 'n holistiese bewussyn gepropageer. Sy publikasie Holism and evolution is heel gepas in 1987 weer uitgegee. Hierdie werk is van belang omdat dit binne die huidige diskussie een bepaalde manier aanbied waarop 'n holistiese bewussyn kan opereer. Die hooflyne van hierdie siening word eers kortliks uiteengesit. Die siening toon egter ook verrassende raaklyne met die beskouing oor totaliteit in Spreuke 1-9. Met die uiteensetting van Smuts se model as raamwerk, word die totaliteitsmodel van Spreuke vervolgens ook uiteengesit. Dit word aangebied as een van die Bybelse denkmodelle wat ook ' $n$ plek in die bespreking van holisme as denkparadigma van die postmoderne tyd behoort te kry.

- Openbare voorlesing gelewer by die opening van die Fakulteit Teologie (Afd A), Universiteit van Pretoria op 4 Februarie 1991. 


\section{SMUTS EN HOLISME}

\section{1 'n Holistiese wêreldbeeld}

Smuts soek na 'n omvattende en universele Weltanschauung. Met behulp van natuurwetenskaplike teorieë soos Darwin se evolusieteorie en die relatiwiteitsteorie van Einstein, probeer hy eerstens die aard van die universum bepaal. Hy kom tot die gevolgtrekking:

[T]his is a whole-making universe...it is the fundamental character of this universe to be active in the production of wholes, of ever more complete and advanced wholes, and that the Evolution of the universe, inorganic and organic, is nothing but the record of this wholemaking activity in its progressive development.

(Smuts 1987:326)

\subsection{Dinamiese holisme}

Smuts het 'n 'synthetic world-conception' (Smuts 1987:52). In hierdie wêreld word dinge altyd na mekaar toe gedryf en op mekaar betrek om saam steeds groter gehele te vorm. Dit is egter geen eenmalige of afgehandelde saak nie. Oor miljoene jare is deur evolusie uit basiese materie gehele gevorm wat weer as deelsisteme verbind om steeds groter en ingewikkelder kombinasies van gehele te vorm. Dit is 'n progressiewe proses van 'creative synthesis' (Smuts 1987:104) waarin voortdurend unieke nuwe kombinasies ontstaan wat oor funksies en eienskappe beskik wat nie in hulle dele teruggevind kan word nie. Soos wat al meer verwikkelde gehele geskep word en evolusie opheweeg na al hoër kategorieë van samestellings, word die strukture al meer skeppend van aard en bring dit al meer en al ingewikkelder sinteses tot stand. Na hiérdie kreatiewe proses verwys Smuts as 'holisme'. Dit is 'the principle which works up the raw material or unorganised energy units of the world, utilises, assimilates and organises them, endows them with specific structure and character and individuality, and finally with personality, and creates beauty and truth and value from them' (Smuts 1987:107).

Die wêreld is vir Smuts 'n sintetiese, strukturele, aktiewe, vitale en al verder skeppende geheel. Die wêreld is geen statiese geheel nie. Dit vorm ook nie een groot geheel omdat alles daarin een of ander gemeenskaplike substansie deel nie. Dit is eerder besig om in ruimte en langs die as van die tyd steeds lewend en kreatief na die ondenkbare hoogtes van nuwe gehele te beweeg. Omdat alles in die heelal aan daardie holistiese proses deel het, word alles saamgesnoer tot eenheid. Deelname aan hierdie proses is vir Smuts die samesnoerende verband van alles in die heelal. Smuts se sienswyse van die geheel kan dus as 'dinamiese holisme' gekenmerk word. 


\subsection{Progressiewe skepping}

Die proses van geheelvorming (holisme) is vir Smuts 'n 'epigenesis' (Smuts 1987:9), 'n dinamiese, evolusionêre en kreatiewe proses en nie 'n eksplikasie nie. Die filosofiese standpunt dat die somtotaal van die werklikheid 'n konstante is, dat die gang van die wêreld 'n eksplikasie is van dit wat reg aan die begin gegee is, of hoogstens 'n hergroepering en herrangskikking van oorspronklike groeperings is, verklaar nie vir hom die werklikheid waarmee ons te doen het nie. Hy sien eerder die kreatiewe proses van holisme as iets waardeur die somtotaal van die werklikheid progressief toeneem in die skep van al meer gehele en al meer gekompliseerde eenheidstrukture. Daar was aan die begin ' $n$ basiese patroon wat die verdere evolusie van die wêreld bepaal het en wat voorkom dat daar bloot'n rigtinglose energie of tendens aan die werk is. Dit neem egter nie weg dat skepping nog steeds voortgaan nie. Tewens, dit is ' $n$ voortgaande proses waarin kreatiwiteit eerder toeneem as afneem.

\subsection{Teleologiese holisme}

Hierdie teleologiese beklemtoning geld ook vir die verstaan van die gehele wat gevorm word. Smuts konsentreer op die tweede aspek van Darwin se teorie oor die ontstaan van spesies, naamlik dié van 'variasie'. In kreatiewe evolusie moet mutasies nie vanuit die basiese elemente waaruit hulle gevorm is, verstaan word nie. Die basiese element moet eerder in terme van die resulterende evolusievorm gesien word. Die mutasie behou wel die basiese eienskappe, maar deur die interaksie van hierdie dele ontstaan daar nou ook eienskappe wat nooit vroeër daar was nie. Die samevoeging van die elemente waterstof en suurstof laat 'n nuwe struktuur, naamlik water ontstaan. Water het fisiese en chemiese eienskappe wat nie in die elemente waterstof of suurstof aanwesig is nie. Liggaamsorgane snoer die selle waaruit dit opgebou is, saam tot 'n orgaan wat weer in die groter lewensgeheel van die liggaam opgaan. Die nuwe geheel waarop die evolusie uitloop, die waarheen van die proses eerder as die waaruit word die basis van waaruit die geheel verstaan moet word. Dit geld alle vlakke van geheelvorming, selfs die vlakke van die geestelike en personale gehele, hoeveel ingewikkelder en subtieler dan ook al.

\subsection{Progressiewe geheelvorming}

Smuts onderskei die gehele wat ontstaan in hiërargiese kategorieë. Die verskillende soorte gehele wat progressief oor die tyd heen opgebou is, verdeel hy in vier kategorieë: materie, lewe, gees en personaliteit. Dit is egter nie disparate fenomene nie. Die kategorieë vorm 'a more or less connected progressive series of the same great Process [with] a fundamental continuity...' (Smuts 1987:21). In elke kategorie is die gehele gevorm deur 'n soortgelyke holistiese proses. Dieselfde proses laat egter al- 
tyd die gehele van een kategorie uitmond in dié van die volgende kategorie. Materie is 'n massa energie en aktiwiteit. Deur permutasies en kombinasies van materie word 'n oneindige variasie van molekulêre strukture geskep. Uit die omvorming van hierdie strukture in nog groter en ingewikkelder strukture ontstaan gehele in die kategorie lewe. Holistiese evolusie van gehele uit die kategorie lewe verdig weer in nog ingewikkelder gehele binne die kategorie van die denke of gees en hulle muteer in die hoogste kategorie van gehele wat daar tans bekend is, die van personaliteit.

\subsection{Antropologie}

In die lig hiervan huldig Smuts 'n heel bepaalde mensbeskouing. Tussen die mens en die wêreld bestaan 'n noue verbintenis. Die mens is 'n geheel wat deur die holistiese evolusie van elemente uit die natuur tot stand gekom het. Tussen mens en wêreld is daar 'n kreatiewe genetiese harmonie. Terwyl die mens egter uit die wêreld kom, is hy in sy resulterende eindvorm 'n eiesoortige geheel. Daar is nie 'n animistiese verwantskap tussen die mens en die wêreld nie. Hy deel ook nie een of ander gemeenskaplike grondelement of geesteselement met die ander gehele in die wêreld nie. Soos elke ander geheel is die mens so 'n intense eenwording van dele wat so 'n digte verknoping tussen dele en geheel is, dat dit prakties onmoontlik word om in die finale struktuur dele en geheel skerp van mekaar te onderskei. Dit beteken dat daar nie oor die mens dualisties gedink kan word nie. Dit is 'n naïewe dualisme om aan die mens te dink as liggaam en siel, 'n anima wat in 'n corpus bly. Biochemiese en psigo-fisiese dele is by die mens in 'n unieke eenheid saamgestruktureer tot harmonieuse funksionering in 'n enkele geheel waarvan die dele nie los van die geheel verstaan kan word nie. Elke deel funksioneer in terme van die geheel en met die oog op die geheel. Die mens is 'n onlosmaaklike geheel.

\subsection{Die mens binne 'n groter geheel}

As 'n uniek gevormde geheel dra die mens egter nog steeds in homself die basiese holistiese strewe wat in elke ander geheel voorkom. Hy streef daarna om nog groter en omvattender gehele te skep deur met sy omgewing in interaksie te tree. Die onderskeidende aard van geestelike gehele is egter dat hulle rasioneel funksioneer. Danksy daardie feit werk die mens as geestelike geheel nie in die rigting van eiesinnige aktiwiteit nie, maar veral na inskakeling by die universele orde van die wêreld. Rasionaliteit is die bepaalde uitingsvorm van die universele holistiese tendens in die mens-geheel. Die mens se rede is expressive of universality; it is part of that Order which regulates the universe and in a deep sense it is a creative factor or co-creator of that Order' (Smuts 1987:243). 
Deur alles wat hy ervaar en wat hy ken met mekaar in verband te bring, vind die mens selfvervulling. Die mens vind homself wanneer hy homself sien in terme van sy plek binne die groter geheel. Smuts (1987:246) sê: '[T]he individual self only comes to its own through the rational and social self which relates it organically to the rest of the universe.'

\subsection{Personaliteit}

Die suksesvolle integrasie van die mens by sy wêreld om 'n groter en afgeronder geheel te vorm, noem Smuts die geheel van die personaliteit ('personality'). Dit is die volledigste mutasie van holisme, die hoogste en mees volledige geheel wat daar kan bestaan. Hierin kulmineer alle laere gehele van materie, lewe en gees in 'n verhouding van 'peraksie' of 'intro-aksie' (Smuts 1987:270) binne een holistiese geheelstruktuur. Die persoonlikheidsgeheel is 'a balanced whole or structure of various tendencies and capacities which are maintained in mutual and reciprocal harmony by the holistic nature of the Personality itself (Smuts 1987:295). Die aktiwiteit van holisme is voortdurend in die personaliteitsgeheel aan die werk om liggaam en gees, hart en verstand, wil en emosie kollektief te harmonieer tot een integrale geheel. Dit wil homself realiseer deur intellektueel, moreel en sosiaal te assimileer. Dit assimileer wat nodig is vir steeds groter heelheid en vermy dit wat die suksesvolle groei na heelheid kan benadeel. Ervaring, optredes, beslissings en oortuigings word kreatief omgewerk in artistieke, etiese en geestelike waardes. Vir Smuts is holistiese selfrealisering en perfeksie van die persoonlikheidsgeheel binne die universele holistiese orde (Smuts 1987:315) daarom ook die mikpunt waarheen gestreef moet word. Op spreukagtige wyse makk hy die oproep: 'Learn to be yourself with perfect honesty, integrity and sincerity; let universal Holism realise its highest in you as a free whole of Personality; and all the rest will be added unto you - peace, joy, blessedness, happiness, goodness, and all the other prizes of life' (Smuts 1987:315).

\section{TOTAI JTEIT IN SPREUKE 1-9}

\subsection{Totaliteitsbeeld en totaliteitskonsepte}

Die onderliggende perspektief van die leergedigte in Spreuke 1-9 is totalisties van aard. Dit beskou sake in terme van omvattende gehele. Dit gaan oor die vorming van die hele mens, oor sy verhouding met alles wat saam met hom in die wêreld is en oor sy aandeel aan die harmonieuse orde wat die hele kosmos bymekaarhou. Hierdie gedagtegang word in begrippe uitgedruk wat in die gedigte as totaliteitskonsepte funksioneer. Daar is drie kernbegrippe: spreuke, wysheid en lewe. Vervolgens word die hooftrekke van die totaliteitsmodel van Spreuke aan die hand van elkeen van hierdie drie begrippe uiteengesit. 


\subsection{Spreuke}

Die geformuleerde spreuke is die kollektiewe ervaring van die voorgeslagte wat onder woorde gebring is. Die ouers en die leermeesters het uit'n hele leeftyd van ervaring die resep geformuleer hoe om suksesvol te lewe. Hulle is oortuig dat dit die formule is waarvolgens God wil hê die mens moet lewe. Hierdie formule word nou in die vorm van verskillende slagspreuke aan die leerling aangebied om sy totale menswees daarvolgens te vorm. Dit rig appèl tot sy rede, gevoel en wil. Dit sit by hom 'n omvattende proses aan die gang wat sy ganse bestaan raak. Dit berei hom voor vir elke moontlike situasie wat hy te enigertyd mag teenkom. Hy moet uiteindelik ' $n$ mens word wat self in 'n verhouding van wysheid tot alles rondom hom staan. Wanneer hy dit gerealiseer het begin hy werklik lewe. Dan staan hy in die regte verhouding met God en smaak hy die vreugde wat die Here vir sy skepping bedoel het.

Hierdie spreuke funksioneer opvallend totalisties of holisties. Soos by Smuts gaan dit ook hier oor 'n holistiese proses. Dit gaan om die hele mens en sy verhouding met alles wat hy teenkom. Die uitkoms van die saak is in beide gevalle 'n sinvolle geheel, ' $n$ universele orde. Daar is egter ' $n$ verskil in die beskouing oor wat alles in die eindgeheel ingesluit is. Vir die spreukemodel is die suksesvolle verhoudings met die totale werklikheid boonop ook nog die regte verhouding met God. Om in wysheid te leef is tegelykertyd om die Here te dien (Spr 1:7; 2:5). Die interrelasie van mens en wêreld dra die addisionele kwaliteit van geloofsrelasie met God wat uiteraard nie in die Smuts-model voorkom nie. Anders as by ander holistiese modelle beteken dit nie dat die grense tussen mens en Godheid vervloei nie. God en mens en wêreld behou elkeen hulle selfstandigheid. Uit die tot standbring van die regte verhouding tussen al die partye egter, kom die harmonie waarin die geheel en elk van sy dele volle verwesenliking vind. God se wil en eer kom tot sy volle reg in die geïntegreerde funksionering van die totale kosmos. Die mens staan in die regte verhouding met God juis omdat hy funksioneel integreer in daardie kosmos waarin God hom geplaas het. Die wêreld bied die optimum van sy vermoë omdat die bedoeling van God daarmee verwesenlik word in die regte verhouding tussen mens en kosmos.

Verskil die siening oor die aard en kwaliteit van die totaliteit, word die proses ook anders gesien. Die aard van die proses by spreuke is nie evolusionêr nie. Dit gaan ook nie oor 'n proses wat net van binne uit gerig en bepaal word nie. By spreuke is dit eerder 'n proses van koördinasie tussen uiterlike dryfvere en innerlike motivering. Die proses word van buite die mens geïnisieer en gestimuleer om 'n doelwit te bereik wat buite die mens alleen staan. Nie uit bepaalde historiese gebeure nie, maar uit die herhalende alledaagse gebeure 'openbaar' die spreuke dit 
aan die mens dat die wil van God in die suksesvolle interaksie van mens en wêreld geleë is. Die mens moet oorreed en gemotiveer word om sy plek in die wêreld te vind. Eksterne oorsaak en doel versmelt egter in die proses met interne motivering. In hierdie literatuur word spreuke soms baie naby aan identies met wysheid en wysheid identies met lewe geskets. Sodra die mens hierdie spreuke sy eie gemaak het, word hy ' $n$ wyse mens wat uit innerlike motivering begin soek na die eenheid en verband met die wèreld waartoe die spreuke hom opgeroep het. In Smuts se terme kan ons sê dat daar uit die 'mutasie' van spreuke en mens 'n geheel ontstaan wat soek na die voltrekking van 'n groter geheel met die wêreld. Hierdie soektog na die groter geheel is egter geen selfgesentreerde genotsug van die mens nie. Dit moet eerder teleologies vanuit die eindresultaat gesien word: Wanneer die mens sy plek in die wêreld vind, vind die mens tegelyk ook sy plek voor God en vind hy homself.

\section{Wysheid}

Die spreuke maak van die mens iemand wat wys en verstandig is. 'Wysheid is die bestaanswyse wat God vir die mens gewil het, waarin die mens met insig en vernuf homself suksesvol en gelukkig kan uitleef binne die verhouding met God en binne die verbande waarin Hy alles in die geskape wêreld tot mekaar gestel het' (Venter 1981:313). Aan die grond van wysheid lê die saak van verhouding en die dinamiese aktualisering van verhoudings. Dit behels egter meer as net die eerste model se rasionele akkommodasie van die werreld in die geheel van die persoonlikheid. Wysheid omvat buiten kennis ook nog gesindheid, diskresie, meelewendheid en lewensvaardigheid. Dit is belydenis en belewenis ineen. Dit is die effektiewe inskakeling van die gehele mens by die geheel van die wêreld waarin hy leef.

Die verhouding tussen die mens en die wêreld word hier gesien as funksionele inskakeling by mekaar. Wanneer die mens homself in die regte verhouding tot alles stel, kom daar uit die suksesvolle interaksie van mens en dinge die harmonie voort wat die dinge goed maak en die mens werklik laat lewe. Alles word nie 'n mutasie wat in die mens opgaan nie. Mens en dinge behou eerder hulle selfstandigheid. Hulle kom tot 'n samewerkingsooreenkoms waaruit die harmonie ontstaan wat aan elke deelnemer die geleentheid gee om tot sy volle potensiaal te kom. Tussen mens en wêreld is daar dus nie kreatiewe genetiese harmonie soos in die eerste model nie, maar gerealiseerde harmonie soos God dit gewil het.

Die inskakeling van die dele van die kosmos, mens en wêreld, by mekaar om 'n groter geheel te vorm, word hier ook anders gesien as by die eerste model. Die ervaring van die wese van dinge het geleer dat alles eers hulle doel bereik wanneer hulle op die regte wyse met mekaar skakel. Dit gebeur egter nie spontaan omdat hulle bepaalde eienskappe deel nie, maar vanweë die gemeenskaplike van hulle 
bruikbaarheid vir God. Die Here het hulle op mekaar gerig en by die skepping gemaak om saam met mekaar die geheel van die kosmos te vorm. Hier is sprake van koördinerende en inklusiewe kategorieë eerder as van gehele wat as deelsisteme progressief in mekaar opgaan en in 'n hoogste kategorie kulmineer. In spreuke word wel hoër en laer kategorieë onderskei. Wysheid bring byvoorbeeld meer winste as edelstene of goud (Spr 3:14.15). In die meer basiese kategorie is daar sake soos goud, geld, rykdom, eer, gesondheid en 'n lang lewe. Die elemente van 'n laer kategorie word dan opgeneem in ' $n$ hoêr en omvattender kategorie. In die proses verloor dit egter nie selfstandigheid nie en gaan ook nie verlore in die hoëre kategorie nie. Binne die hoër kategorie kom dit selfs vir die eerste keer tot realisering. 'n Hoër kategorie, soos dié van wysheid, sluit die laer kategorie nie uit nie, maar juis in. Die wyse mens het nie net lewe en insig nie, maar hy het ook rykdom, gesondheid en geluk. Die mees omvattende kategorie van lewe sluit binne die volkomenheid van 'n verhouding met die Here wysheid, geluk, eer, aansien, gesondheid en rykdom in.

In 'n sekere sin is daar ook hier sprake van teleologiese holisme. Die proses is eers voltrek wanneer die omvattendste geheel bewerkstellig is. Maar die eindgeheel is nie hier 'n oneindige mutasie van selfskeppende holisme nie. Die finale punt waarop hierdie proses afstuur, is die eksplikasie van God se skeppingswil wanneer die mens sy plek vind in die wêreld en die samehang van die geheel uitgesorteer is. Hierdie proses gaan egter nie by die punt verby waar dit voorheen by die voorgeslagte uitgekom het nie. Daar is 'n versadigingspunt waar die doel bereik is en die mens die soort mens word wat God wil hè dat hy moet wees. Die geheelvorming wat hier plaasvind wanneer die formule vir die regte verhouding tussen mens en wêreld gevind word, is geen kreatiewe holisme soos in die eerste model nie; eerder gerealiseerde totaliteit. Dit gaan nie hier oor 'n epigenesis waarin die somtotaal van die werklikheid progressief toeneem nie. Die somtotaal is daarenteen ook nou weer nie 'n konstante nie, maar ' $n$ veranderlike wat tussen twee pole beweeg. Wanneer die mens doen wat hierdie spreuke aanbeveel, kom die geheel tot sy reg en werk alles soos God dit bedoel het. Die feit dat hierdie spreuke die proses aan die gang moet sit, wys egter op die ander pool: Daarsonder bly die mens vasgevang in onkundige selfgesentreerdheid en kom daar niks tereg van 'n suksesvolle interrelasie van alles in 'n harmonieuse geheel nie. Tussen hierdie pole van orde en wanorde, van wyse en dwase mense, van lewe en dood, fluktueer die somtotaal van die kosmos. Vanuit die ordeloosheid moet elke mens wat in die wêreld kom opnuut die tog aanpak na realisering van orde in sy lewe.

Omdat die aard van die proses in hierdie model anders is as by die van Smuts, impliseer dit dat die aandeel van die mens aan hierdie realiseringsproses ook anders 
gesien word. Smuts (1987:243) is van mening dat die mens deur sy rasionele inset 'co-creator' is van die universele orde. Hy speel veral in die personaliteitsgeheel die sentrale rol. In die wysheidsnavorsing word al vir dekades lank debat gevoer oor die vraag of wysheid die herkenning van 'n bestaande orde is of die vermoë om orde in die wèreld te skep. In Spreuke 1-9 is daar van albei sprake. Die spreuke hou aan hom 'n orde voor wat al vantevore gerealiseer is, maar dring tegelyk by hom aan om self weer daardie orde in sy lewe te realiseer. Die wysheid wat die spreuke by hom teweeg wil bring, is nie iets wat hy passsief ontvang nie, maar iets wat hy doelbewus moet kultiveer. Die wysheid, veral waar dit gepersonifieer (of gehipostaseer) word (Spr $1: 20-33 ; 3: 13-20 ; 8: 1-36 ; 9: 1-19$ ), is iets wat die mens moet toeêien, 'n noue verbintenis mee aangaan (Spreuke 7:4), wat die mens in sy eie lewe moet aktualiseer totdat hy self ook wys is. Die mens moet sy wysheid toepas en die suksesvolle relasie met alles realiseer deur sy funksionele verhouding tot alles. Die aktiewe rol van die mens blyk ook daaruit dat hy 'n keuse het of hy die spreuke ter harte wil neem of nie. Sonder sy aandeel kom daar niks tereg van 'n suksesvolle interaksie nie. Die mensgesentreerdheid van die proses is egter ' $n$ illusie. Wat die mens realiseer, is geen nuwe skepping nie, maar dieselfde suksesvolle simbiose wat vorige geslagte en die formuleerders van die spreuke in hulle eie lewe alreeds bereik het (Spr 1:1-7; 4:1-9). Meer nog, wat hy deur sy inset realiseer, is 'n orde waarin hy alleen verwesenliking kan vind as hy hom aan die wil van God en aan die dissipline van medewerking met die res onderwerp. Vanuit die eindgeheel gesien, is sy rol dié van aktiewe medewerker.

\subsection{Lewe}

Met 'lewe' word die gerealiseerde sintese van mens en wêreld aangedui. Lewe 'is die sinvolle saamordening van alles waaruit die menslike lewe maar kan bestaan.. die hoogste verhewenheid waartoe menslike eksistensie maar kan styg' (Venter 1981:329). Spreuke wat tot konkrete lewensverhoudings omgebou is, lei tot lewe in die volste sin van die woord. Prakties toegepaste wysheid lei tot 'n lewe van interaksie met die ganse wêreld. 'Lewe' is die werkende interaksie van die geheel. Dit is die beskerming en bewaring van die eie lewe onder allerlei lewensgevare (Spr 1:819). Dit is sekuriteit en die vermoë om in teenspoed staande te bly (Spr 1:20-33; 3:21-26). Dit is 'n hegte verbintenis met God en 'n dienooreenkomstige lewe op 'n hoë sedelike peil (Spr 2:1-22; 3:27-35; 4:10-19, 20-27; 9:1-18). Dit is 'n lang lewe wat aansien, goeie gesondheid en materiële welvaart insluit (Spr 3:1-12; 5:1-23). Dit hou geestelike rykdom in wat materiële skatte nie uitsluit nie (Spr 3:13-20). Dit is die bestaanswyse van 'n fyn opgevoede persoon wat erkentlikheid geniet (Spr 4:1-9). 
Dit is die gedissiplineerdheid van huwelikstrou (Spr 6:20-35; 7:1-27). Dit sluit beroepsukses, mag, insig, eer, eiendom en regsinnigheid in (Spr 8:1-36).

Uit die integrering van mens en wêreld in een harmonieuse geheel, uit die suksesvolle sintese van die dele, kom 'n geheel voort wat eienskappe het wat nie in die dele aanwesig was nie. Daar kom 'n orde na vore, 'n harmonie, wat aan die dele 'n funksie en kwaliteit gee wat hulle nooit op hulle eie kan hê nie. Albei modelle is dit eens dat die mens eers voluit mens word wanneer hy binne hierdie geheel funksioneer. Menswees is om mens te wees binne die groot geheel. Ook die dinge van die wêreld vind eers hulle werklike waarde wanneer die mens hulle in hierdie geheel geïntegreer het. Vir die totaliteitsmodel van Spreuke is die summum bonum van God se wil in die funksionele integrasie van alles binne hierdie grootste geheel geleë.

Die mensbeeld hou hier met totaliteit verband. Die mens neem aan die proses van geheelvorming in die totaliteit van sy persoon deel. Op tradisioneel Semitiese wyse word die mens as 'n geheel gesien sonder dat daar geestelike of fisiese komponente in hom onderskei word. Hy skakel by hierdie hoëre harmonie met die totaliteit in van sy hele menswees en baat ook in die totaliteit van sy menswees daarby: liggaamlik, geestelik en godsdienstig; meer nog, die mens word werklik mens wanneer hy by die harmonie van hierdie hoëre orde inskakel. Die menslikheid van die mens word juis in die verhoudingsinskiklikheid na buite gevind. Dit is die mens wat soek na die regte verhouding na buite - met die wêreld, met dinge en mense en met God - wat begin lewe. Hy is die wyse mens wat die resep vir die lewe en selfverwesenliking gevind het. Hy doen dit wat God wil hê en realiseer die bedoeling van God met die mens en die wêreld. Hy volg die reëls wat God vir menswees gestel het en is die een wat 'werklik kan lewe' (Spr 4:4). Daarteenoor staan die mens wat hierdie verhoudings laat skeef loop en alleen gerig is op selfsugtige motiewe. Hy verloor alles, ook sy menswaardige bestaan en vind die 'dood'. Die mens wat nie mens is nie, wat nie die harmonie na buite soek waarin hy selfverwesenliking kan vind nie, vervreem homself van die wêreld en dehumaniseer homself. $\mathrm{Hy}$ is dood vir homself, vir die wêreld en eventueel ook vir God.

\section{SLOTWOORD}

Die model waarmee Smuts gewerk het, is 'n model van dinamiese holisme. Dit is 'n filosofiese model wat vanuit filosofiese vertrekpunte selfs as 'onoortuigend' (Du Toit 1987:472) beoordeel kan word. Dit bevat egter verrassende raaklyne met die model in Spreuke 1-9. As verwysingsraamwerk gebruik, het dit meegehelp om die model in Spreuke noukeuriger te omskryf. 
Die totaliteitsmodel van Spreuke werk met 'n realiseerbare totaliteit. Dit is 'n teologiese model wat ook saam met die ander teologiese modelle van die Bybel gelees moet word. Hierdie model is positivisties van aard en moet saam met boeke soos Job en Prediker gelees word. Daar word nie vanseffsprekend aangeneem dat die mens uit eie ervaring die wil van God so deeglik kan peil dat hy die pad na die harmonie van die finale totaliteit sonder meer kan bewandel nie. Intertekstueel moet dit weer saam met die modelle van die Nuwe Testament gelees word waar die pad na gerealiseerde totaliteit op verskillende wyses aan die persoon van Jesus Christus verbind word. Vanuit daardie verhouding met God in Christus kan ons teologiseer hoe dit moontlik is om God se mens te word in die wêreld. Binne 'n groter model van geheelheid kan die model van Spreuke die pad aantoon na 'n gerealiseerde totaliteit waarin die mens kosmies betrokke kan word wat hy behoort te wees.

\section{Literatuurverwysings}

Du Toit, A P 1987. J C Smuts (1870-1950), in Faure, A M, Gey van Pittius, A C A, Kriek, D J, Louw, A du P \& Wainwright, E H (reds), Die Westerse politieke tradisie, 463-474. 2e hersiene uitgawe. Pretoria: Academica.

Schoeman, M J 1990. Holisme: Die herowering van 'n ou wysheid in 'n moderne konteks. HTS 46, 267-292.

Smuts, J C 1987. Holism and evolution. Kaapstad: N \& S Press.

Venter, P M 1981. Spreuke, wysheid en lewe in Spreuke een tot nege. DD-proefskrif, Universiteit van Pretoria. 